\title{
How can we battle the scourge of diarrhea? 2003 McKenna Memorial Lecture
}

\author{
Kim E Barrett PhD
}

\begin{abstract}
KE Barrett. How can we battle the scourge of diarrhea? 2003 McKenna Memorial Lecture. Can J Gastroenterol $2003 ; 17(11): 667-672$.

Diarrheal diseases exact a considerable toll of morbidity and mortality worldwide, including in developed countries where the incidence of foodborne illness, in particular, may be increasing. This article summarizes the current understanding of the basis of diarrheal illness, focusing particularly on intracellular signaling mechanisms that limit the extent of intestinal epithelial chloride secretion, which may offer new targets for antidiarrheal therapies. Recent information regarding the mechanisms whereby invasive bacteria cause diarrhea is also reviewed along with effects of beneficial bacteria (so-called probiotics) in limiting dysfunction associated with enteric infections. Finally, the author provides some speculations as to the possible benefits to the host of mounting a diarrheal response to an offending pathogen, and possible consequences of the failure of this primitive host defense mechanism.
\end{abstract}

Key Words: Chloride secretion; Diarrheal disease; Intestinal epithelial cells; Probiotics; Salmonellosis

\section{Comment lutter contre le fléau de la diarrhée? Conférence commémorative McKenna 2003}

La maladie diarrhéique s'associe à un taux considérable de morbidité et de mortalité de par le monde, y compris dans les pays en voie de développement, où l'incidence de maladies d'origine alimentaire, notamment, serait à la hausse. Le présent article résume la compréhension actuelle des assises de la maladie diarrhéique et porte surtout sur les mécanismes de signalisation intracellulaire qui limitent la portée des sécrétions intestinales de chlorure, lesquelles peuvent constituer de nouvelles cibles pour les traitements antidiarrhéiques. Des données récentes sur les mécanismes par lesquels les bactéries envahissantes provoquent la diarrhée sont également examinées, de même que les effets des bactéries bénéfiques (les prétendus probiotiques) à limiter la dysfonction associée aux infections entériques. Enfin, l'auteur spécule sur les bénéfices possibles pour l'hôte d'une réponse diarrhéique croissante face à un pathogène offensant et sur les conséquences éventuelles de l'échec de ce mécanisme primitif de défense de l'hôte.
$\mathrm{D}$ arrheal diseases have been a scourge to humanity throughout recorded history. In the Western world, diarrhea may be only an inconvenience, although one that makes the sufferer miserable and which has considerable economic impact $(1,2)$. In developing countries, on the other hand, diarrheal diseases are second only to pneumonia as a cause of infant mortality beyond the neonatal period (3). Moreover, even in the absence of mortality, diarrheal diseases in infancy have demonstrable long term consequences, including malnutrition, reduced physical fitness and impaired cognitive function and school performance (4). The toll such diseases take on human capital is therefore immense and, even in developed countries, several groups are at increased risk for severe outcomes of diarrheal illnesses, and there is evidence that disease incidence is increasing $(5,6)$. Many diarrheal diseases are infectious in origin, and the rapid emergence of antibiotic resistance among causative pathogens is lending increased urgency to the search for a greater understanding of disease pathogenesis in the hope of developing new treatments $(7,8)$.

This article is derived from a presentation made at the 2003 meeting of the Canadian Association of Gastroenterology. My goals are to discuss the scope of the problem, to review basic mechanisms of diarrhea, and to summarize some recent work from my laboratory that has elucidated intracellular mechanisms that regulate intestinal secretory function and the ability of invasive bacteria to inteact with these mechanisms to cause disease. It was a great honour to be selected as the 2003 McKenna lecturer and I thank the officers of the Canadian Association of Gastroenterology, and especially its President, Dr Philip Sherman, for this singular recognition.

\section{THE SCOPE OF THE PROBLEM}

The burden of diarrheal diseases, and particularly those caused by enteric infections, is immense. Infections are estimated to account for 3 to 4 billion cases of diarrhea each year, and up to 4.3 million deaths in children under the age of five years $(3,4)$. Even in developed countries, the very young, the very old, institutionalized individuals, and those persons with compromized immune systems are at risk for severe or even fatal outcomes of diarrheal illness (5). In fact, foodborne diseases alone have been estimated to cause approximately 5000 deaths annually in the United States, along with more than 300,000 hospitalizations and more than 76 million episodes of diarrheal illness (6). Only a fraction of these cases involve known pathogens, but, of these, more than $90 \%$ are attributable to three main causes - Norwalklike viruses, Campylobacters and nontyphoidal Salmonella species (6). Nontyphoidal Salmonellae also account for almost a third of food-related deaths from diarrheal illness (6). 
The economic burden represented by this massive disease prevalence is immense, being estimated conservatively in the United States at more than US $\$ 8$ billion per year in 2000 dollars; other countries report proportionately similar impacts $(1,2)$. Moreover, there is evidence to suggest that foodborne illnesses are increasing in incidence. Several reasons have been put forward to account for this, including increased antibiotic use in animals, the global trade in food and consolidation of markets, a substantial increase in international travel, an increase in vulnerable populations, changes in what and where we eat, an ignorance of basic food preparation techniques caused by societal changes, and the failure of regulatory and control mechanisms to adapt to these stresses $(5,6,9)$. Indeed, in the United States, only 2000 inspectors are available to analyze imported food (5). Finally, antibiotic resistance is now rampant among the pathogens most frequently identified as causative agents of diarrheal disease in developing countries, suggesting that new treatments are urgently needed if we are to have any impact at all on this epidemic before more comprehensive improvements in living conditions $(7,8)$.

In addition to foodborne infections, many other intestinal disorders are associated with diarrheal symptoms (10). Chief among these in terms of numbers are likely the functional bowel disorders, where the etiology of diarrhea is unknown but may relate to fundamental changes in intestinal motility. Other diarrheal diseases, on the other hand, may be associated with a significant degree of mucosal, and specifically, epithelial dysfunction. Examples include the diarrhea associated with inflammatory bowel diseases and food allergies, and iatrogenic diarrhea associated with the use of broad-spectrum antibiotics and/or acquired in the hospital setting that is most commonly ascribed to overgrowth of Clostridium difficile (11). But no matter what the cause, an understanding of most diarrheal illnesses rests on knowledge of basic intestinal transport mechanisms (10).

\section{BASIC MECHANISMS OF DIARRHEA}

The intestine is an organ that dynamically controls the amount of fluid in its lumen (10). This is accomplished by a balance of passive secretion and absorption of water across the intestinal epithelium, driven in turn by the active vectorial transport of electrolytes and other solutes. In general, the transport properties of intestinal epithelial cells evolve as they migrate along the crypt-villus axis. While it is somewhat of an oversimplification, secretory functions are most prominent in the crypt, and absorptive properties are subsequently acquired by the differentiated enterocytes of the villus tips (10). Absorptive fluxes are driven primarily by sodium-coupled uptake of specific nutrients like glucose and, to a lesser extent, sodium chloride (10). Fluid secretion, on the other hand, is driven predominantly by the active electrogenic secretion of chloride ions, with a smaller contribution provided by secretion of bicarbonate (10).

The segregation of secretory and absorptive functions allows their simultaneous expression, and thus the minute-tominute control of luminal fluidity based on physiological demands related, for example, to the ingestion of a meal. When considered as a whole, however, the balance of fluid and electrolyte transport in the gut is normally absorptive. Very little (less than $200 \mathrm{~mL}$ ) of the approximately $9 \mathrm{~L}$ of fluid presented to the intestine on a daily basis (from either oral intake or various secretions) is lost in the stool (10). In the setting of diar- rhea, on the other hand, this normal balance is lost. The absorptive reserve capacity of the intestine is overwhelmed and the amount of water lost to the feces increases, in some cases dramatically (eg, losses of up to $20 \mathrm{~L} /$ day in cases of cholera) (10). This increase in fecal water results from an increase in fecal solutes, which can be due to a reduction in the absorption of salt and nutrients, an increase in crypt chloride secretion or, most commonly, some combination of both, so that net secretion occurs. In addition, maldigestion of ingested nutrients and alterations in epithelial barrier function may also contribute to fluid losses, and the pathogenesis of most cases of diarrhea is probably multifactorial, especially for those evoked by enteric infections (12).

In recent years, a considerable understanding of the molecular basis for transport mechanisms has emerged. Thus, sodiumcoupled absorption of glucose (and, by analogy, several other nutrients) originates at the apical membrane via the sodiumglucose cotransporter, SGLT-1 (10). The driving force for this uptake is a low intracellular sodium concentration established by $\mathrm{Na}^{+} / \mathrm{K}^{+}$-ATPase in the basolateral membrane. Glucose then exits basolaterally via a facilitated diffusion glucose transport pathway (GLUT-2). In between meals, when nutrients are not available, water absorption can alternatively be driven by the coupled uptake of chloride and sodium across the apical membrane via the downregulated in adenoma (DRA) chloride/bicarbonate exchanger and the sodium/hydrogen exchanger (NHE-3), respectively (10). Again, this process is dependent on the $\mathrm{Na}^{+} / \mathrm{K}^{+}$-ATPase and probably also involves basolateral chloride exit across a potassium/chloride cotransporter (putatively identified as KCC1).

Considering fluid secretion, chloride uptake from the bloodstream across the basolateral membrane of crypt epithelial cells is mediated by a sodium/potassium/2 chloride cotransporter, NKCC1, which responds to the low intracellular sodium concentration established by the sodium pump. Potassium accumulated within the cytosol is recycled across the basolateral membrane via specific channels, whereas chloride exits the cell apically, via either cystic fibrosis transmembrane conductance regulator (CFTR) chloride channels or possibly (in lesser amounts) via additional chloride channels, such as the CLCA channels that are regulated by calcium (10). Both potassium and chloride channels serve as control points for the regulation of secretion, and can be activated by specific second messengers, such as cAMP, cGMP and calcium (10). Interestingly, cAMP has also been shown to inhibit NHE-3 (13). Thus, in a disease like cholera, where there is an irreversible increase in cAMP levels in intestinal epithelial cells, diarrhea is likely worsened by the simultaneous stimulation of chloride secretion and inhibition of sodium chloride absorption. Notably, however, sodium-coupled nutrient absorption remains intact, providing a rationale for treatment with oral rehydration solutions (14).

\section{INTRACELLULAR REGULATION OF EPITHELIAL SECRETORY FUNCTION}

We and other investigators have explored intracellular messengers that regulate secretory transport, with the hope that we might discover pathways that could be exploited to treat diarrheal symptoms. Cyclic nucleotides induce significantly larger and more prolonged increases in chloride secretion than does elevated cytosolic calcium $(15,16)$. Moreover, if epithelial cells are presented with combinations of agonists acting through 
these two pathways, a synergistic enhancement of chloride secretion occurs, leading us to speculate that calcium-dependent responses represent the 'fine-tuning' of the system. Thus, intracellular mechanisms that modulate calcium-dependent secretion have the ability to markedly affect overall transport rates in vivo. Among such mechanisms, we have extensively explored signaling pathways that focus on the receptor for epidermal growth factor (EGF).

EGF itself has been known for some time to exert significant effects on intestinal transport. Studies reveal that this prototypic growth factor can stimulate absorption of sodium chloride and nutrients, and also decrease chloride secretion $(17-20)$. The net effect of these actions is to conserve fluid and electrolytes. Moreover, because EGF receptors and relevant ligands (including EGF itself and transforming growth factoralpha $[T G F \alpha]$ ) may be regulated in the setting of intestinal injury and inflammation, the beneficial effects of EGF on net fluid transport may represent an adaptive response that protects the body from excessive fluid loss $(21,22)$. We have shown that EGF inhibits chloride secretion via an intracellular signaling pathway that sequentially recruits the enzymes phosphatidylinositol 3-kinase and protein kinase $\mathrm{C}$ to the basolateral membrane of secretory epithelial cells, ultimately limiting chloride secretion by reducing the activity of a basolateral potassium channel $(23,24)$. If potassium cannot be recycled across this membrane, the driving force for chloride exit through apical chloride channels is lost.

We have also identified a possible role for the EGF receptor in accounting for the transient nature of secretion evoked by calcium-dependent chloride secretagogues, such as acetylcholine. Thus, cholinergic agonists appear to activate an autocrine signaling loop that results in the release of TGFo from intestinal epithelial cells, in turn resulting in activation of the EGF receptor and recruitment of downstream kinases, such as the extracellular signal-regulated protein kinase (ERK), isoforms of mitogen activated protein (MAP) kinases. These also seem capable of inhibiting secretion, albeit via mechanisms and targets that have yet to be defined. In a similar vein, growth hormone, a major mediator of somatic cell growth and a possible therapy for diarrhea and tissue injury in Crohn's disease, is also capable of limiting epithelial chloride secretion via a mechanism that involves the EGF receptor and ERK MAP kinases (25).

We are beginning to develop an understanding of the complex set of integrated signalling events that cooperate to limit the extent of epithelial chloride secretion in intestinal epithelial cells, details of which are provided in Figure 1. The significance of these findings lies in the knowledge that chloride secretion is demonstrably subject to inhibitory as well as stimulatory regulatory mechanisms, and the former might be exploited for antidiarrheal therapy. Likewise, growth factors and their receptors emerge as critical mediators of antisecretory signaling, and small molecule activators of consequent signals may be suitable as antidiarrheal drugs.

\section{EFFECTS OF INVASIVE PATHOGENS ON INTESTINAL EPITHELIAL CELL FUNCTIONS}

Let us now consider the mechanisms of diarrheal disease caused by invasive bacterial pathogens. Invasive bacteria account for more than half of the mortality due to foodborne illness in the United States, yet we are only beginning to understand how they cause diarrhea (6). This lack of understanding contrasts

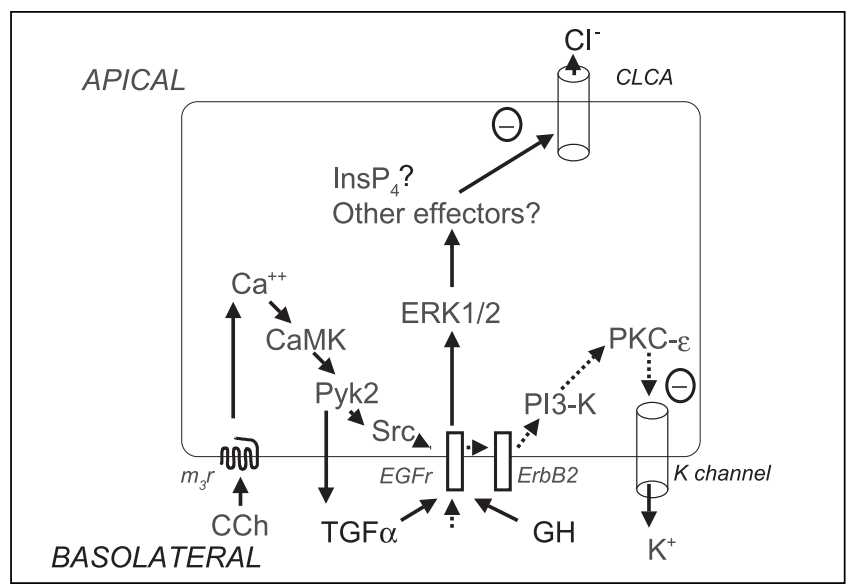

Figure 1) Signaling pathways shown to be involved in the negative regulation of calcium-dependent chloride secretion across intestinal epithelial cells. Epidermal growth factor (EGF) itself can reduce chloride secretion via effects on a basolateral potassium channel, as shown by the broken arrows. This pathway involves heterodimerization of the activated EGF receptor with another related family member, ErbB2. The acetylcholine analogue carbachol (CCh), on the other hand, acts initially to stimulate transient chloride secretion but subsequently transactivates the EGF receptor via a signaling cascade that cleaves active transforming growth factor-alpha (TGF $\alpha$ ) from a membrane-bound precursor. In an ErbB2-independent manner, the activated EGF receptors recruit extracellular signal-regulated protein kinase (ERK) isoforms of mitogen activated protein kinases that, via pathways that have yet to be fully elucidated, eventually block chloride secretion by interacting with a calcium-activated apical chloride channel (CLCA). Finally, growth hormone $(\mathrm{GH})$ also appears to utilize the EGFr and ERK MAP kinases to reduce secretion. It likely does so by binding initially to its own receptor and subsequently recruiting effectors capable of EGF receptor transactivation (not shown here). Additional details are provided in the text. CaMK Calmodulin-activated protein kinase; InsP $P_{4}$ Inositol 3,4,5,6-tetrakisphosphate; PI3-K Phosphatidylinositol 3kinase; PKC Protein kinase C

with that for diarrhea caused by enterotoxigenic bacteria. The latter release soluble toxins into the intestinal lumen, thereby altering epithelial function without mucosal invasion. Examples include cholera and enterotoxigenic Escherichia coli, the latter being the major causative agent of traveler's diarrhea (5). Therefore, we have initiated studies that seek to define the mechanisms of diarrhea produced by invasive bacteria, especially Salmonella typhimurium, which is prevalent in both developed and developing countries (6).

We first studied signaling events that occur rapidly when $S$ typhimurium bacteria encounter the apical membrane of intestinal epithelial cells grown in culture. Interestingly, in light of the foregoing discussion, the bacteria cause a prompt, yet transient, activation of the EGF receptor (26). This occurs in a manner that is independent of bacterial invasion, as assessed by using mutant bacterial strains that lack the capacity to invade, yet can still bind to epithelial cells $(26,27)$. This activation of the EGF receptor appears to be secondary to the bacterium's ability to mobilize intracellular calcium, which might otherwise be expected to stimulate chloride secretion. Indeed, we have shown that the ability of Salmonella to cause early activation of the EGF receptor is responsible for limiting 


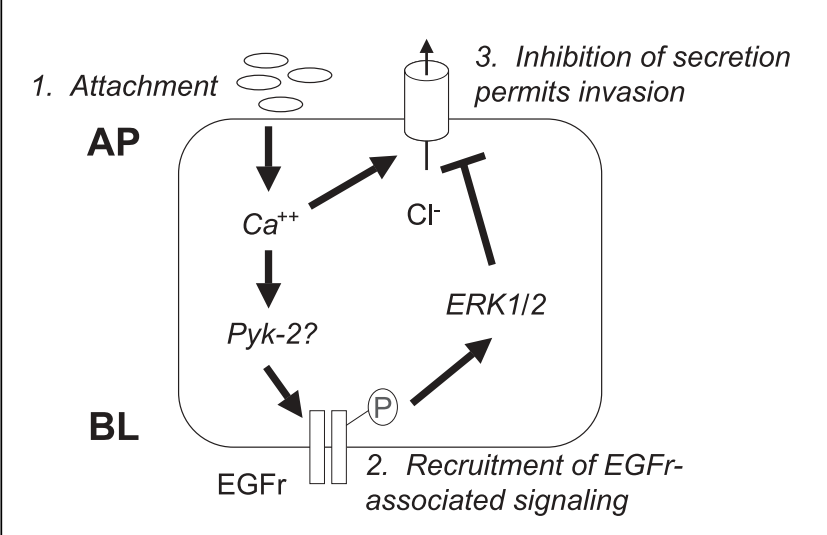

Figure 2) Early (seconds to minutes) signaling events that occur in intestinal epithelial cells infected with Salmonella typhimurium, and their consequences. Bacteria bind to the apical membrane of polarized epithelial cells (1), thereby elevating cytosolic calcium, which ordinarily would activate chloride secretion. The bacterially-evoked increase in cytosolic calcium, however, simultaneously results in phosphorylation of the epidermal growth factor receptor (EGFr), perhaps via the calciumsensitive soluble tyrosine kinase, Pyk-2, thereby leading to subsequent EGFr-related signaling events. These are then presumed to countermand the prosecretory signal that might otherwise increase chloride secretion, and we hypothesize that the inhibition of secretion is required to allow bacterial invasion (3). Further details are provided in the text. AP Apical; BL Basolateral

ongoing chloride secretion (26). We speculate, therefore, that the recruitment of EGF receptor-dependent signaling events that limit calcium-dependent chloride secretion allows the Salmonella infection to become established by preventing the short burst of chloride (and accompanying fluid) secretion from washing away the bacteria before they are able to invade (Figure 2). While these data do not explain why patients infected with $S$ typhimurium experience diarrhea, they may elucidate the mechanisms for initial colonization and evasion of host defenses.

On the other hand, at later times (hours to days) after the addition of $S$ typhimurium to epithelial cell monolayers, there is a significant increase in the rate of spontaneous chloride secretion, which might correlate with the diarrheal response in vivo (28). Infected epithelial cells also show heightened secretory responses to a variety of cAMP-dependent and other chloride secretagogues, such as galanin, further exacerbating fluid loss. The increases in both basal and stimulated secretion appear to result from the sequential induction of expression of inducible nitric oxide synthase (iNOS) and cyclooxygenase-2 (COX-2) (28). In turn, the products of these enzymes not only elevate cyclic nucleotide second messengers that are capable of directly stimulating chloride secretion, but also cause increased expression of CFTR and NKCC1, resulting in a hypersecretory phenotype (28). Finally, infected cells have impaired barrier function, which also appears to depend on iNOS (but not COX-2) induction (28). This phenomenon probably further contributes to diarrhea in vivo by rendering the epithelium incapable of sustaining the electrochemical gradients needed for absorptive fluxes. The later effects of Salmonella infection

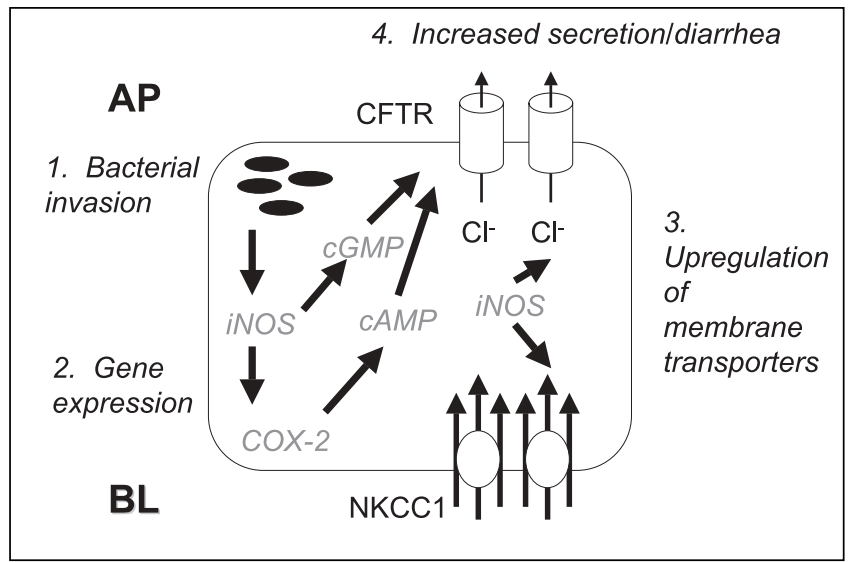

Figure 3) Late (hours to days) signaling events that occur in intestinal epithelial cells infected with Salmonella typhimurium, and their consequences. Following bacterial invasion (1), signals delivered by the bacteria result in the sequential upregulation of inducible nitric oxide synthase (iNOS) and cyclooxygenase-2 (COX-2) (2). Mediators produced by these enzymes (nitric oxide and prostanoids) elevate intracellular cGMP and cAMP, respectively, resulting in stimulation of apical cystic fibrosis transmembrane conductance regulator (CFTR) chloride channels and consequent chloride secretion. Inducible nitric oxide synthase (iNOS) activity also leads to increased expression of CFTR and the sodium/potassium/2 chloride cotransporter, NKCC1, and their insertion into the membrane (3), further amplifying the hypersecretory phenotype and possibly contributing to diarrhea (4). Further details are provided in the text. AP Apical; BL Basolateral

that may account for the diarrheal responses are depicted in Figure 3

We also examined whether probiotic bacteria, commensals that exert health benefits beyond inherent nutrition if ingested in certain numbers, are capable of altering signaling events and their functional outcomes induced in epithelial cells by invasive pathogens. We undertook these studies because there is significant anecdotal evidence that probiotic preparations alleviate the symptoms of intestinal infections and other digestive disorders like inflammatory bowel diseases, yet there is a paucity of information about their mechanism(s) of action. Our studies have revealed that probiotics are capable of causing a sustained increase in barrier function in intestinal epithelial cell lines, and can also attenuate the decrease in transepithelial resistance that is produced by infection with invasive bacteria (29). Likewise, probiotic strains also limit the increase in baseline chloride secretion that occurs after prolonged infection with invasive pathogens (29). Finally, while invasive bacteria, in later stages after infection, cause a decrease in the ability of EGF to signal via its receptor, the addition of probiotics to the culture abrogates this presumed deleterious response to infection (29). It appears that probiotics exert these effects by a number of complementary mechanisms, such as interference with pathogen adhesion and direct interactions with the epithelial cells themselves (29). In any event, the studies provide justification for the use of probiotics, at least in the setting of enteric infections, and indicate that ongoing work to maximize the beneficial effects of various probiotic strains should be fruitful. Patients readily accept probiotics and they are usually well tolerated, often being 
comprised of bacterial strains (eg, Lactobacilli) that have been used in the preparation of food for millennia (30).

\section{SHOULD WE BATTLE THE SCOURGE?}

I will finally make some points about the potential benefits to the host of a diarrheal response, based in part on some new studies we have initiated with another invasive pathogen, Salmonella typhi. This organism is very closely related to $S$ typhimurium at the genetic level, yet causes a quite different clinical picture (31). Thus, while $S$ typhimurium produces disease that is essentially limited to the gastrointestinal tract in normal individuals, with significant diarrhea, S typhi usually causes typhoid fever, a disease that is characterized by sepsis due to rapid bacterial dissemination to extraintestinal sites, but with little or no diarrhea (31). We have shown that, unlike $S$ typhimurium, $S$ typhi fails to elicit a delayed hypersecretory response in infected intestinal epithelial cells, and has qualitatively different effects on epithelial cell signaling (32). We speculate, therefore, that the diarrheal response to $S$ typhimurium may represent a protective adaptation that limits additional bacterial invasion. In the absence of such a response, as seen with $S$ typhi, the host may be rendered susceptible to ongoing bacterial invasion followed by disseminated infection. Further studies, currently ongoing in our laboratory, will be required to confirm or refute our hypothesis. Nevertheless, the preliminary findings are intriguing in that they are consistent with the long-held, but unproven, view that diarrhea is beneficial to the host because it reduces the infectious load as well as the luminal concentration of toxins and other injurious agents. Before according universal enthusiasm for this primitive host defense mechanism and its benefits, we must ask ourselves which party stands to gain the most in the equation. The diarrheal response also represents a mechanism for spreading disease to additional individuals, to say nothing of the risk it represents to the initial victim in terms of dehydration and electrolyte imbalance. Thus, particularly in vulnerable hosts like young children, this 'protection' may come at too high a price.

\section{CONCLUSIONS}

Diarrhea remains a worldwide scourge, and its prevalence and impact is also under-recognized and perhaps increasing even in developed countries. Studies from our laboratory, as well as many others, are beginning to reveal the spectrum of mechanisms that are exploited by invasive pathogens, which complements our understanding of enterotoxigenic diarrheal disease. We may also gain a greater understanding of the benefits of the diarrheal response, which has implications for the treatment of diarrhea in otherwise healthy individuals. Likewise, an improved understanding of epithelial transport physiology may lead to the development of more rational treatments, such as those that target signaling events related to growth factor receptors. Conversely, it may lead to a greater knowledge of the rationale for old therapies, such as probiotics, that enjoy wide patient acceptance due to their 'natural' provenance and an apparently excellent safety profile. However, it is humbling to realize that improvements in public health and sanitation will have a far greater effect on the impact of diarrheal disease in the poorest countries of the world (4). Unsafe and inadequate water for basic hygiene place billions of children at risk and account for the vast majority of deaths from diarrheal disease (3).

ACKNOWLEDGEMENTS: I acknowledge the ongoing hard work and inspiration provided by current and former members of my research group, some of whose findings are specifically discussed herein, including: Lone Bertelsen, Alfred Chappell, Jimmy Yip Chuen Chow, Cornelia Gelbmann, Raschid Hoda, Stephen Keely, Declan McCole, Silvia Resta-Lenert, Jane Smitham, Wolfgang Tillinger, Jorge Uribe and Glenda Wheeler. The collaborative assistance of my colleagues, Lars Eckmann, Don Guiney and Robert Coffey, has also been crucial to some of the projects described. I am grateful to have the opportunity also to recognize the contributions of three outstanding mentors who nurtured my research career through graduate studies, postdoctoral work, and my first years as a faculty member: Frederick L Pearce of University College, London, Dean D Metcalfe at the National Institutes of Health, USA, and the late Kiertisin Dharmsathaphorn, who was the first to instill in me a fascination with intestinal epithelial biology and its clinical implications. Finally, I must acknowledge ongoing funding for this work from the National Institutes of Health (USA) and the Crohn's and Colitis Foundation of America, without whose generous support none of the work would have been possible.

\section{REFERENCES}

1. The Lewin Group. The Burden of Gastrointestinal Diseases. Bethesda: American Gastroenterological Association, 2001.

2. Sandler RS, Everhart JE, Donowitz M, et al. The burden of selected digestive diseases in the United States. Gastroenterology 2002;122:1500-11.

3. Black RE, Morris SS, Bryce J. Where and why are 10 million children dying every year? Lancet 2003;361:2226-34.

4. Guerrant RL, Kosek M, Moore S, Lorntz B, Brantley R, Lima AAM. Magnitude and impact of diarrheal diseases. Arch Med Res 2002;33:351-5.

5. Bishai WR, Sears CL. Food poisoning syndromes. Gastroenterol Clin N Am 1993;22:579-608.

6. Mead PS, Slutsker L, Dietz V, et al. Food-related illness and death in the United States. Emerg Infect Dis 1999;5:607-25.

7. Davis MA, Hancock DD, Besser TE. Multiresistant clones of Salmonella enterica: The importance of dissemination. J Lab Clin Med 2002;140:135-41

8. Hamer DH, Gill CJ. From the farm to the kitchen table: The negative impact of antimicrobial use in animals on humans. Nutr Rev 2002;60:261-4.

9. Redmond EC, Griffith CJ. Consumer food handling in the home: A review of food safety studies. J Food Prot 2003;66:130-61.

10. Montrose MH, Keely SJ, Barrett KE. Electrolyte secretion and absorption: Small intestine and colon. In: Yamada T, Alpers DH, Kaplowitz N, Laine L, Owyang C, Powell DW, eds. Textbook of Gastroenterology. Philadelphia: Lippincott Williams and Wilkins, 2003:308-39.

11. Thomas C, Stevenson M, Riley TV. Antibiotics and hospitalacquired Clostridium difficile-associated diarrhoea: A systematic review. J Antimicrob Chemother 2003;51:1339-50.

12. Powell DW. Approach to the patient with diarrhea. In: Yamada T, Alpers DH, Laine L, Owyang C, Powell DW, eds. Textbook of Gastroenterology. Philadephia: Lippincott, Williams and Wilkins, 1999:858-909.

13. Weinman EJ, Steplock D, Donowitz M, Shenolikar S. NHERF associations with sodium-hydrogen exchanger isoform 3 (NHE3) and ezrin are essential for cAMP-mediated phosphorylation and inhibition of NHE3. Biochemistry 2000;23:6123-9.

14. Farthing MJ. Oral rehydration: An evolving solution. J Pediatr Gastroenterol Nutr 2002;34(Suppl 1):S64-7.

15. Donowitz M, Welsh MJ. Ca ${ }^{2+}$ and cyclic AMP in regulation of intestinal Na, $\mathrm{K}$, and $\mathrm{Cl}$ transport. Annu Rev Physiol 1986;48:135-50. 
16. Chu S, Montrose MH. Extracellular $\mathrm{pH}$ regulation in microdomains of colonic crypts: Effects of short-chain fatty acids. Proc Natl Acad Sci USA 1995;92:3303-7.

17. Opleta-Madsen K, Hardin J, Gall DG. Epidermal growth factor upregulates intestinal electrolyte and nutrient transport. Am J Physiol 1991;260:G807-14.

18. Hardin JA, Buret A, Meddings JB, Gall DG. Effect of epidermal growth factor on enterocyte brush-border surface area. Am J Physiol 1993;264:G312-8

19. Uribe JM, Gelbmann CM, Traynor-Kaplan AE, Barrett KE. Epidermal growth factor inhibits $\mathrm{Ca}^{2+}$-dependent $\mathrm{Cl}^{-}$secretion in T84 human colonic epithelial cells. Am J Physiol 1996;271:C914-22.

20. Donowitz M, Janecki A, Akhter S, et al. Short-term regulation of NHE3 by EGF and protein kinase $\mathrm{C}$ but not protein kinase $\mathrm{A}$ involves vesicle trafficking in epithelial cells and fibroblasts. Ann NY Acad Sci 2000;915:30-42.

21. Hormi K, Cadiot G, Kermorgant S, et al. Transforming growth factor-alpha and epidermal growth factor receptor in colonic mucosa in active and inactive inflammatory bowel disease. Growth Factors 2000;18:79-91

22. Hoffmann P, Reinshagen M, Zeeh JM, et al. Increased expression of epidermal growth factor-receptor in an experimental model of colitis in rats. Scand J Gastroenterol 2000;35:1174-80.

23. Uribe JM, Keely SJ, Traynor-Kaplan AE, Barrett KE. Phosphatidylinositol 3-kinase mediates the inhibitory effect of epidermal growth factor on calcium-dependent chloride secretion. J Biol Chem 1996;271:26588-95.

24. Chow JY, Uribe JM, Barrett KE. A role for protein kinase Cepsilon in the inhibitory effect of epidermal growth factor on calcium- stimulated chloride secretion in human colonic epithelial cells. J Biol Chem 2000;275:21169-76.

25. Chow JYC, Carlstrom K, Barrett KE. Growth hormone reduces chloride secreton in human epithelial colonic cells via EGF receptor and ERK 1/2 MAPK. Gastroenterology 2003; 125:1114-24.

26. Bertelsen LS, Noviello CM, Guiney DG, Barrett KE. Early, invasion-independent signaling events alter ion transport but not resistance in Salmonella-infected intestinal epithelial cells. Gastroenterology 2002;122:A88. (Abst)

27. Park A, Bertelsen LS, Guiney DG, Barrett KE. Role of Salmonella effector proteins sipB and sipC in altered barrier and transport properties of human intestinal epithelium. Gastroenterology 2003;124:A112. (Abst)

28. Resta-Lenert S, Barrett KE. Enteroinvasive bacteria alter barrier and transport properties of human intestinal epithelium: Role of iNOS and COX-2. Gastroenterology 2002;122:1070-87.

29. Resta-Lenert S, Barrett KE. Live probiotics protect intestinal epithelial cells from the effects of infection with enteroinvasive Escherichia coli (EIEC). Gut 2003;52:988-97.

30. Dunne C, Murphy L, Flynn S, et al. Probiotics: From myth to reality. Demonstration of functionality in animal models of disease and in human clinical trials. Antonie van Leeuwenhoek 1999;76:279-92.

31. House D, Bishop A, Parry C, Dougan G, Wain J. Typhoid fever: Pathogenesis and disease. Curr Opin Infect Dis 2001;14:573-8.

32. Bertelsen LS, Guiney DG, Barrett KE. Comparison of early signaling events and physiological consequences in Salmonella typhimurium- and typhi-infected intestinal epithelial cells. Gastroenterology 2003;124:A476. (Abst) 


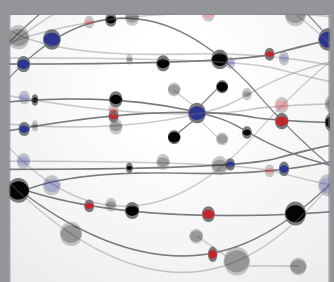

The Scientific World Journal
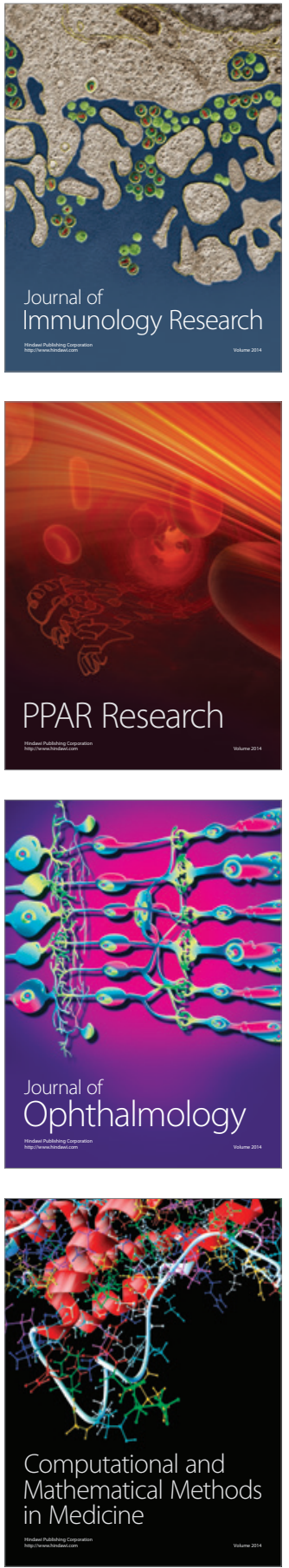

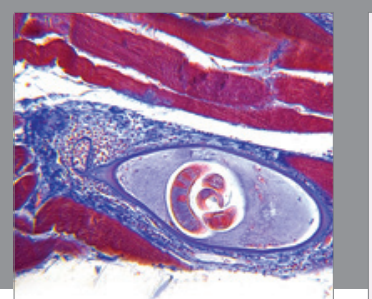

Gastroenterology Research and Practice

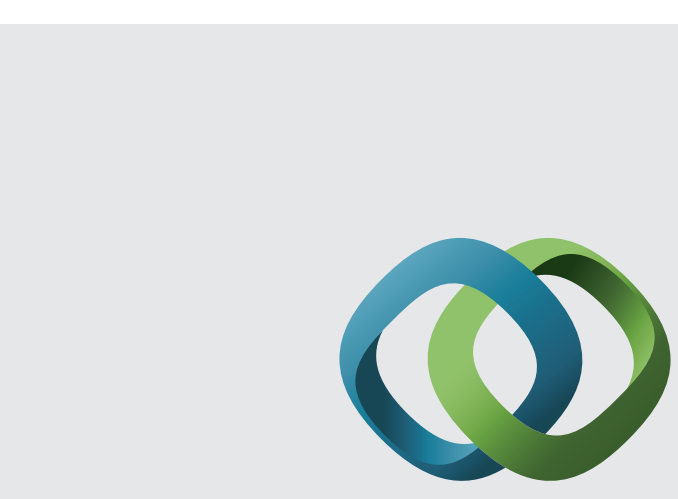

\section{Hindawi}

Submit your manuscripts at

http://www.hindawi.com
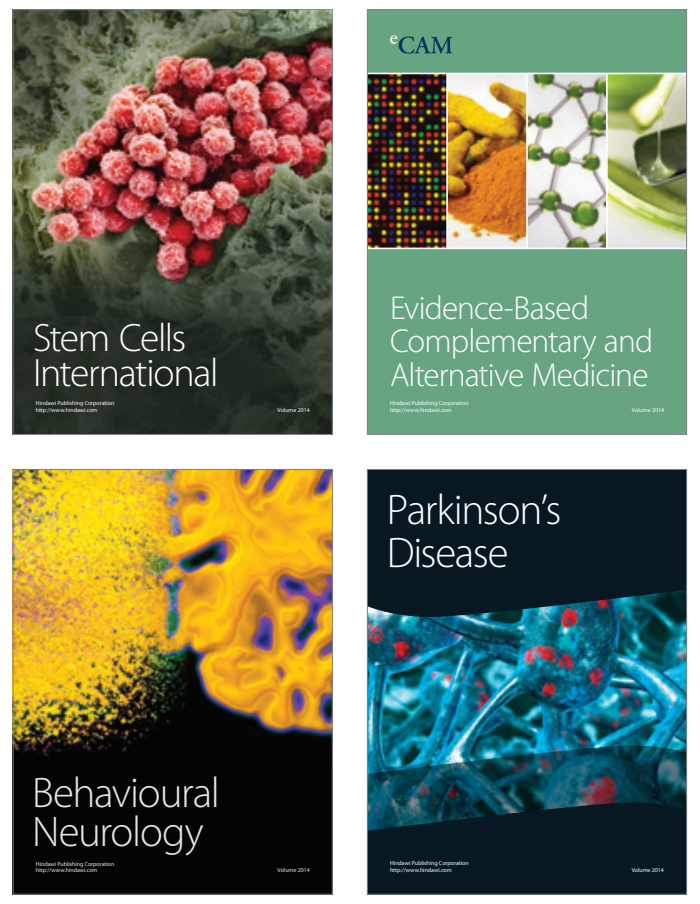
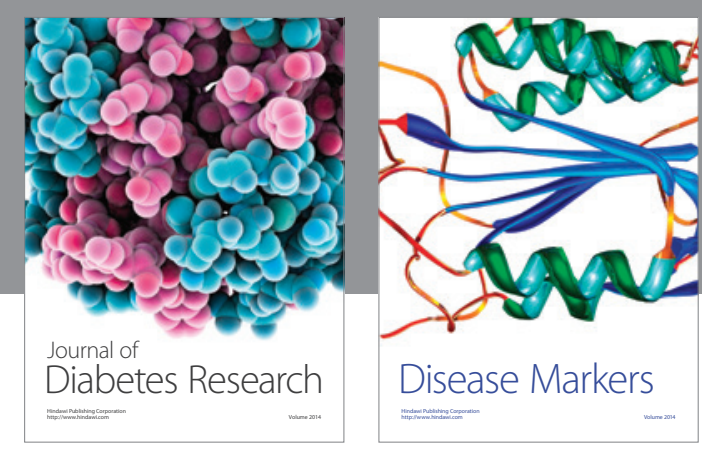

Disease Markers
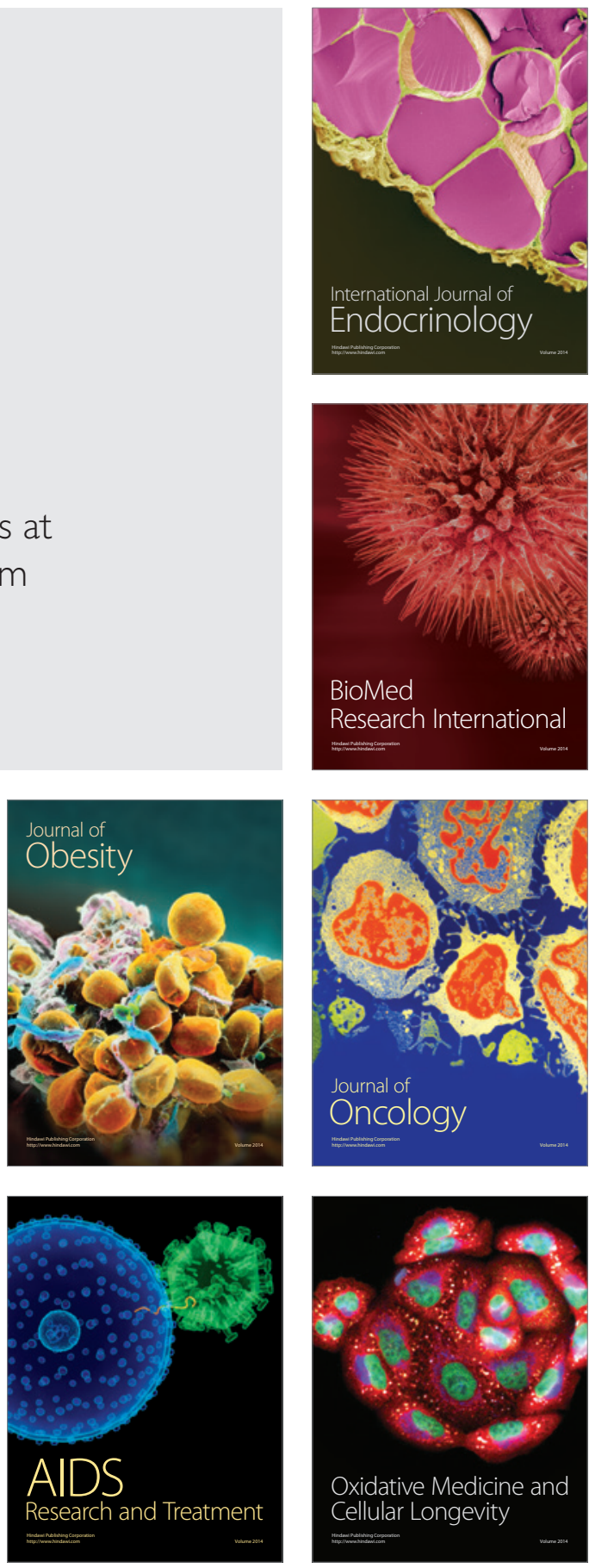